\title{
The Assessment Of Multi-Touch Hand GeSTURES TOWARDS FINE MOTOR SKILlS AMONG PRE-SCHOOL CHILDREN
}

\author{
Fadhlina Mohd Razali ${ }^{1}$, Nor Azah Abdul Aziz ${ }^{1}$, Roznim Mohamad Rasli ${ }^{1}$ \\ Syakirah Samsudin ${ }^{2}$, Siti Aisyah Salim ${ }^{3}$ and Nur Farah Zulkefly ${ }^{1}$ \\ ${ }^{1}$ Faculty of Art, Computing and Creative Industry, \\ Sultan Idris Education University, Perak, Malaysia \\ ${ }^{2}$ Department of Biology, Sultan Idris Education University, Perak, Malaysia \\ ${ }^{3}$ Department of Technology Management, \\ Universiti Tun Husseion Onn, Johor, Malaysia
}

\begin{abstract}
This study aims to evaluate the usage of multi-touch hand gestures towards fine motor skills among preschool children. This study implements a mixed methods involving 30 pre-school children aged between 5 to 6 years old from Pusat Asuhan Tunas Islam as respondents for quantitative method and supported by interviewing teachers as qualitative method. The samples consist of multi-touch and single touch gestures groups, leading to a pre-test and a post-test of a Dot-to-dot activity after implementing the "Mari Belajar Bentuk" mobile application. Findings indicate that the post-test mean and multi-touch gestures mean is higher than the pre-test mean and single-touch gesture mean respectively. This shows that the multi-touch hand gestures effects the fine motor skills development which is also supported by interview results. As for conclusion, the multi-touch hand gestures are an essential factor when designing mobile applications for pre-school children.
\end{abstract}

\section{KEYWORDS}

Mobile Application, Multi-Touch Hand Gestures, Fine Motor Skills, Pre-school Children

\section{INTRODUCTION}

A touch-screen technology is an electronic visual display that can detect the presence and location of a touch within the display area. The term generally refers to touching the display of the device by using fingers or hands [1]. The implementation of touch screen technology is not only found in the communication process, yet also in the high level education industry or even early childhood education domain [2]. Although previous researchers began studying on the touch of interaction children in wider scale, but the scope of the researches are differ from others [3]. Most researchers focused on the ability of children to use touch-screen devices such as the iPad and tablet, however, very limited on the effects of technology use towards the psychomotor development of children especially in fine motor skills development.

The use of multi-touch gestures are also a method of giving input on the touch screen that allows two or more fingers to be used simultaneously. Users can manipulate objects and execute instructions in mobile applications only by using their fingers and hands. Obviously, the interaction with multi-touch hand gestures are attractive and enticing to users, especially to young 
The International Journal of Multimedia \& Its Applications (IJMA) Vol.10, No.6, December 2018

children who are naturally acquainted to the new technologies, which will have an intense effect on their learning [4].

Based on previous study conducted by Aziz [5], the early years of children, at the aged of 2 years old, the children are still struggling to make multi touch gestures such as flick, slide, drag and drop, rotate, pinch and spread. Whilst, children aged 3 years old are also having the similar problems during the multi touch gestures of rotate, pinch and spread. This is totally influenced by the development of their fine motor skills which is still at the early stages of learning. By contrast, as for the children aged between 4 to 12 years old, they can successfully perform all of 7 major finger movements namely tap, drag/slide, free rotate, drag and drop, pinch, flick and spread [5]. This is due to the emergence of technology where children in the 21 st century are capable of learning to use touch-screen and make gestures at their own pace.

A study by Agostinho et al. [6] indicate that finger tracing on tablet device could enhance learning performance which support mathematical problem solving. This is supported by a study which postulate that participants in the drag condition are more accurate than those in the tap condition during the completion of a number line estimation task by either tapping or dragging on a tablet [7]. According to Omar [8], mobile technology has becoming a popular trend among young children in Malaysia. The motivation is based on their observation towards their parents, older people and their environments which incessantly deal with this technology $24 / 7$. Thus, these children experience a better learning environment if handled in right way.

Based on the other study by Lin et al. [9] which investigate the relationship between the use of touch screen towards the achievement level of motor development show a positive relationship between active touch screen usage with the increment of children's motor development. The data are collected through an online survey consists of 715 parents with children aged between 6 months to 3 years old. At the age of 19 to 36 months is the age of the first children to use the touch screen and correlated significantly with fine motor skills (stacking blocks) with $\mathrm{p}=0.03$, after accounting for age, sex, mother's occupation (socioeconomic status) and also early age of children motor development (pincer grip). This findings summarize that the use of touch-screen especially scrolling on the display screen influenced the early achievement of the children' fine motor skills development.

A study by Genc [10] shows that parents' sensitivities toward technology use amongst their children varied substantially. In his study, the percentage of parents expressing their disapproval and approval of the use of such tools are represented by $46.88 \%$ and $26.56 \%$, respectively. Only $26.88 \%$ of the parents indicate that they neither agreed nor disagreed. For parents with positive opinions, they believed that these technological tools could assist in developing or improving their children's fine and gross motor skills, cognitive skills, technological knowledge, and visual memory.

Fine motor skills refer on the capability to make movements using small muscles in hands, wrists and fingers. Hence, it is significant to assess the usage of multi-touch hand gestures towards fine motor skills as they perform small movements to interact with the virtual object naturally. Multitouch hand gestures allow children to perform multiple finger gestures such as free rotate, pinch and spread gestures on touch screen designs.

Thus, this study aims to discuss on fine motor skills development of pre-school children affected by mobile applications usage. Children begin to use their hands since the day they are born in order to explore their own bodies and their surroundings. Their fine motor skills continuously develop when the entire body starts to move and become more stable. According to the 
The International Journal of Multimedia \& Its Applications (IJMA) Vol.10, No.6, December 2018

Nachiappan et al. [11], at the early stages of childhood (from 2 years until 6 years old), their large muscles have grown but small muscles are still imperfectly developed.

\section{LiTERATURE REVIEW}

Multi-touch gestures afforded by the touch-screen technology are a new method of interaction that is widely used in many applications running on mobile devices, such as handphones and tablets. In fact, multi-touch gestures are also a means to provide input to the touch screen using two or more fingers simultaneously.

As indicated by Aziz [5], there are 7 commonly gestures used in children's apps which are tap, drag/slide, free rotate, drag \& drop, pinch, flick and spread. However, in most commercialize pre-school mobile apps, the only gestures applied are tap and slide/drag operations [5]. Thus, other multi-touch gestures such as free rotate, pinch and spread gestures are infrequently used. Figure 1, Figure 2 and Figure 3 display the movement of free rotate, pinch and spread gestures implemented on touch screen design.

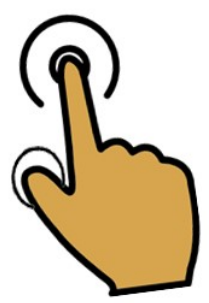

Figure 1. Free rotate gestures on touch screen design

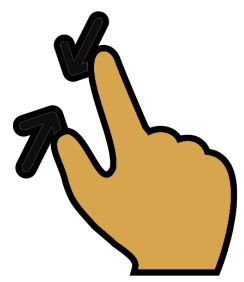

Figure 2. Pinch gestures on touch screen design

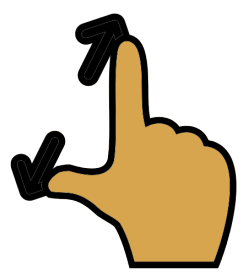

Figure 3. Spread gestures on touch screen design

The free rotate gesture requires the children to twist their fingers whilst the pinch gesture requires the children to use two fingers and bring them closer on the surface. The spread gesture requires the children to touch the surface with two or more fingers and move them apart [5]. Children can rapidly manipulate objects or execute commands by means of their fingers and hands [13]. Children are more open to instruction and more likely to learn by encouraging them to use their hands [14]. Thus, these hands' activities can be considered as an assistive approach in fine motor skills development [15]. 
The International Journal of Multimedia \& Its Applications (IJMA) Vol.10, No.6, December 2018

Fine motor skills are very important in children development. A fine motor skill is needed to help children control a writing instrument steadily. Fine motor skills can be categorized as one of the two types of motor skills, the other one is called gross motor skills which is excluded in this study.

Fine motor skills develop more slowly than gross motor skills. It happens because the kinds of delicate movements that enable children to manipulate objects for example stacking and nesting blocks or putting together puzzle pieces can be learned over a period of time with a lot of practice only.

Fine motor skills are the foundation for children before they learn to write by using their hands (handwriting), in order to have a proper pencil grasp and self-control towards writing instrument [12]. Fine motor skills involve the development of muscles that occur in small movements such as picking up things between the thumb and the fingers, using a pencil or a fork, and other activities that involve the hand, but can also utilize wrists, feet, toes, lips, and tongue.

Fine motor skills are achieved when children learn to use their smaller muscles, like muscles in the hands, fingers, and wrists. Children use their fine motor skills especially when holding small items, buttoning clothing, turning pages, eating and cutting with scissors, which involves handeye coordination.

When combined with the increasing hand-eye coordination, fine motor skills also require exploration, learning, and creative expression. From the learning perspective, activities that encourage the development of fine motor abilities and hand-eye coordination should be given higher priority than those that mere focus on intellectual activities only, such as memorization of letters and numbers. In actuality, fine motor abilities, rather than the ability to count or recite the alphabets, lay the foundation for successful academic learning in later years. For example, learning to write or to draw entails children to have stable, well-coordinated hands to help them hold a pencil steadily [12].

Unfortunately, younger children will run happily for hours on a playground, few really have the patience to sit and copy a drawing of a circle or a cross over and over. The smaller muscles of the body (like those in the hands and fingers) tire out more easily than the larger muscles in the arms and legs, so endurance and strength must be built up gradually before the child's skill can improve [14].

In real life, there are plenty of easy ways to strengthen these muscles, practise co-ordination and develop hand-eye coordination using simple, everyday materials and a bit of creative fun. Preschool children tend to focus more on the process rather than on the product. They throw themselves into exploring the properties and possibilities of materials like paint, mud, sand, water, and glue without worrying about the results [12]. Once the children provided with the tools that inspire creativity, just let them explore the activities, even if things are likely to get rather messy. Table 1 shows the examples of fine motor skill activities which have similar finger movements with multi-touch gestures in mobile apps.

By encouraging children to use their hands is often consider as correct ideas, which then makes them more open to instruction and more likely to learn [14]. As young children move and explore their worlds, they are learning mostly through their touch sensation. 
The International Journal of Multimedia \& Its Applications (IJMA) Vol.10, No.6, December 2018

Table 1. Comparison between ulti-touch gestures and fine motor skill activities

\begin{tabular}{|l|l|l|}
\hline No. & \multicolumn{1}{|c|}{ Multi-touch Gestures } & \multicolumn{1}{c|}{ Fine Motor Skill Activities } \\
\hline 1. & $\begin{array}{l}\text { Free rotate gesture } \\
\text { (Requires the children to } \\
\text { twist their fingers on the } \\
\text { screen). }\end{array}$ & $\begin{array}{l}\text { 1. Van Gogh Style Finger-Paint Printing } \\
\text { Children simply swirling and mixing colors using paint and } \\
\text { fingers. } \\
\text { 2. Lavender and Glitter Sensory Salt } \\
\text { Hands made lovely swirls and patterns. }\end{array}$ \\
\hline 2. & $\begin{array}{l}\text { Pinch gesture } \\
\text { (Requires the children to use } \\
\text { two fingers and bring them } \\
\text { closer on the surface). }\end{array}$ & $\begin{array}{l}\text { 1. Water Drops with Suction Cups } \\
\text { Children use a finger grasp (involve two fingers) to squeeze } \\
\text { one drop of colour water into each little bowl on the dish. }\end{array}$ \\
$\begin{array}{l}\text { 2. Bean Gluing } \\
\text { Children draw a simple picture on a piece of paper with a } \\
\text { pencil. They trace the pencil lines with beads. They glue } \\
\text { the beads onto the design. Gripping the beads with their } \\
\text { fingers is good fine motor practice. }\end{array}$ \\
$\begin{array}{l}\text { Spread gesture } \\
\text { (Requires the children to } \\
\text { touch the surface with two } \\
\text { or more fingers and move } \\
\text { them apart). }\end{array}$ & $\begin{array}{l}\text { 1. Spreading Sand } \\
\text { Sand art is a great fine motor activity because children can } \\
\text { pinch the sand with their fingers and spread the sand to } \\
\text { apply it to their art work. Provide a simple outline or have } \\
\text { the children draw one art work. Then they need to paint } \\
\text { some glue on their art work paper with a glue brushes, } \\
\text { pinch some sand with their fingers, and sprinkle it over the } \\
\text { glue. Sprinkle the sand have similar finger movement with } \\
\text { spread gestures. }\end{array}$ \\
\hline
\end{tabular}

\section{METHODOLOGY}

The implementation of this assessment is guided by a mixed mode methods namely the combination of quantitative and qualitative method. Several phases namely subject's identification, research procedures, research instruments, and the implementation and assessment have been involved throughout this study.

\subsection{SUBJECTS}

In this study, preschool children, aged between 5 and 6 years old has been selected as the research subjects, who are able-bodied with good motor skills. They are recruited with the consents of their parents and the Pusat Asuhan Tunas Islam (PASTI) at Perlis state. The consideration lies on that they would be able to use a mobile application by using their two fingers to touch the display of a mobile device touch-screen quite naturally. The same would not be true if younger children were chosen, because they would most likely touch the screen with both hands which is hard to evaluate the fine motor skills.

\subsection{Procedures}

The selected subjects namely the pre-school children are divided into two groups which are multi-touch gestures group and single-touch gestures group. Respondents are asked to take a pretest (Dot-to-dot activity) to determine their fine motor skills. Then, they are required to learn about the shapes of objects, "Shapes" with two different methods. The first group applied a 
The International Journal of Multimedia \& Its Applications (IJMA) Vol.10, No.6, December 2018

mobile application entitled "Mari Belajar Bentuk" as an exposure to technology. These children are assisted on how to use multi-touch hand gestures to perform the required tasks. They have been given extra time to train themselves with the application and gestures. The second group learnt about "Shapes" by using single touch hand gestures. The learning process has been conducted and observed for two weeks.

Then, the post-test (Dot-to-dot activity) has been conducted to determine these children fine motor skills. The test required them to complete the dotted lines as in the pre-test. The test scores has been recorded based on the observable results of the dotted line activities.

The data is then analysed by using a mixed modes of quantitative and qualitative approaches. Quantitative data (the pre-test and post-test scores, and the multi-touch gestures and single-touch gestures scores) have been analysed by calculating its means. Qualitative data acquired from the interview data has been reported based on the interview questions.

\subsection{INSTRUMENTS}

The main instrument used in this study is the interview questions due to elicit the qualitative data. As for the quantitative data, the pre-test and post-test scores have been calculated (means) based on the use of "Mari Belajar Bentuk" mobile application.

\subsection{The Application}

For this study, the "Mari Belajar Bentuk" mobile application is installed on an Android tablet (see Figure 4), which is then given to selected children (respondents) to use in learning shapes. This mobile application focuses on four main activities namely "Mari Mengenal Bentuk" (Recognizing Shapes), "Teka Bentuk" (Predicting Shapes), "Cari Bentuk" (Searching Shapes), and "Info Produk" (Product Info). The process requires the children to apply multi-touch hand gestures like pinch and spread.

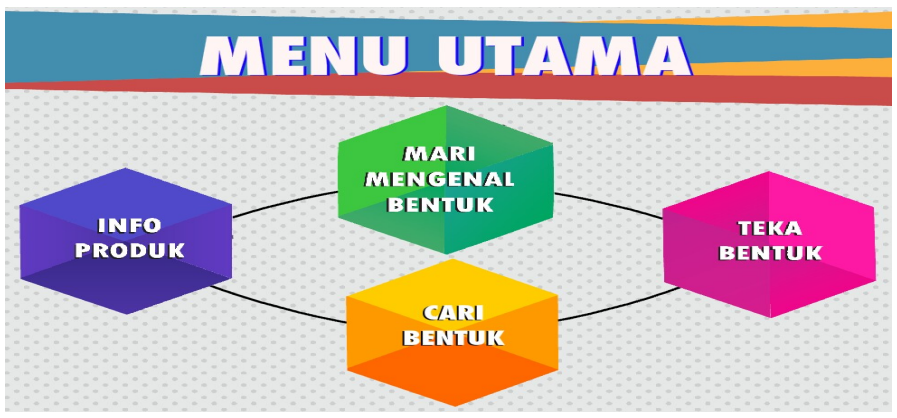

Figure 4. The main menu of "Mari Belajar Bentuk"

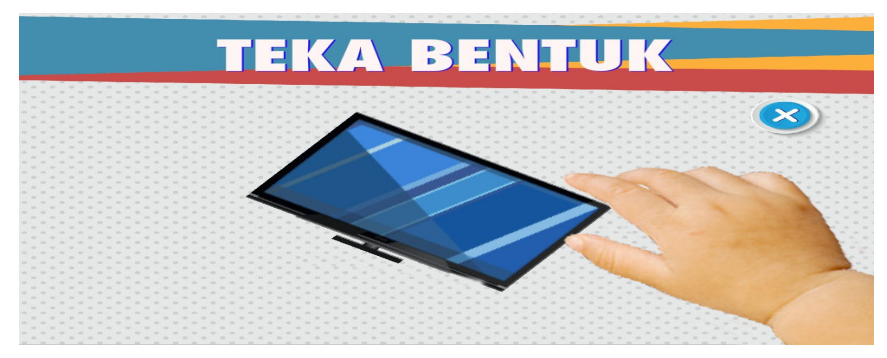

Figure 5. Interacting with shapes by using free rotate gestures 
The International Journal of Multimedia \& Its Applications (IJMA) Vol.10, No.6, December 2018

Figure 5 displays the process of learning the shapes by using the multi-touch hand gestures which highlights on the use free rotate gesture. The learning process involves interaction between respondents and this mobile application.

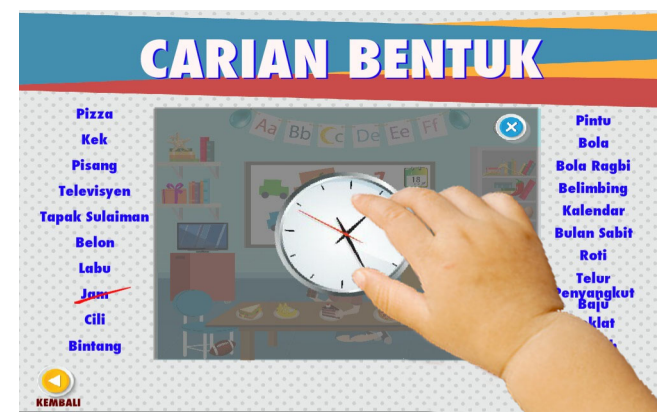

Figure 6. Interacting with shapes with pinch gestures

As in Figure 6, the interaction requires the children to use their hands and apply their fine motor skills to predict the shapes. This is done by applying their multi-touch hand gestures which also highlights on the use of pinch gesture.

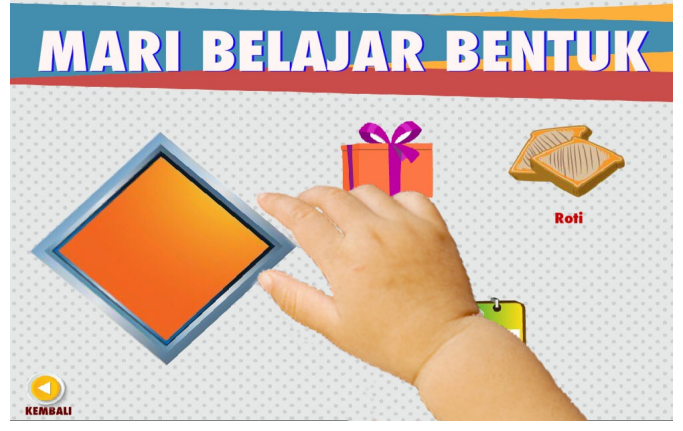

Figure 7. Interacting with shapes by using spread gestures

Figure 7 displays the activity involved in "Mari Belajar Bentuk" where the children is required to search for selected or appropriate shapes. It is shown that in order for the children to find the shapes, spread gestures are also used.

\section{RESULT AND DISCUSSION}

The scope of this study focus on the descriptive statistic such as the mean scores of multi-touch gestures and single touch gestures and the mean scores between the pre-test and post-test, including the interview findings pertaining to the attractiveness, dependability, efficiency, perspicuity, and stimulation.

Specifically, attractiveness refers to the overall impression of users on multi-touch gesture, and dependability is concerned with user control of the multi-touch gesture. Efficiency refers to the ease in performing tasks with the use of the multi-touch gesture, while perspicuity is a measure of the product familiarity when using the multi-touch gesture. Meanwhile, stimulation relates to the motivation of users in using such gesture [16]. As such, the interview questions enabling the researchers to gather all aspects about pre-school children skills and ability in using the multitouch hand gestures with a mobile application. Figure 8, Figure 9 and Figure 10 display some snapshots that had been done in this study. 
The International Journal of Multimedia \& Its Applications (IJMA) Vol.10, No.6, December 2018

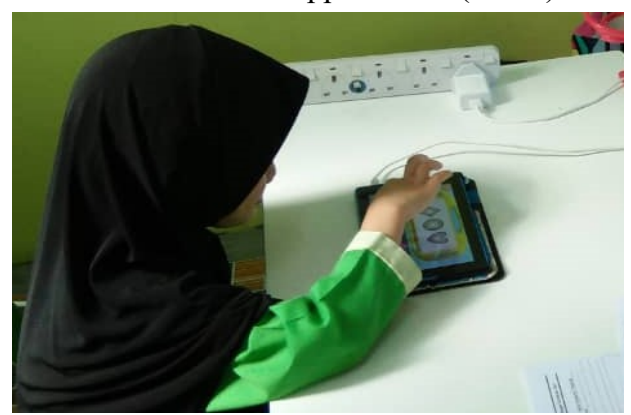

Figure 8. A pre-school child using multi-touch hand gestures to learn about shapes

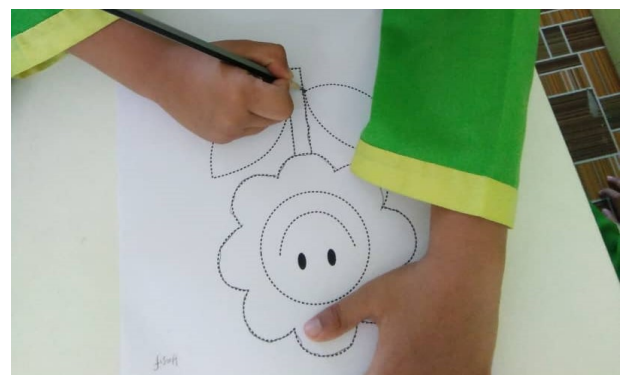

Figure 9. A 5 years old child doing a dot-to-dot activity

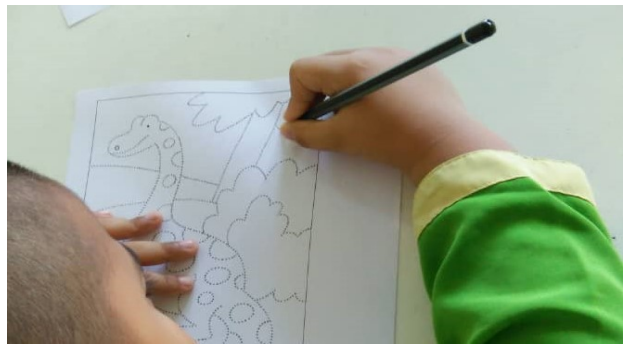

Figure 10. A 6 years old child doing a dot-to-dot activity

The analysed data of test scores indicate that the post-test mean is higher than the pre-test mean. The differences between the pre-test mean and the post-test mean for multi-touch gestures group are larger than the single-touch gestures group. There is only approximately 1 score for the differences between the pre-test mean and the post-test mean of the single-touch gestures group aged 5 years old.

There is no difference between the pre-test mean and the post-test mean of the single-touch gestures group for children aged 6 years old compared to the multi-touch gestures group. The findings also postulate that the multi-touch gestures mean is higher than the single-touch gestures mean. Thus, it can be concluded that the multi-touch hand gestures effect the fine motor skills development. The assessment of the Dot-to-dot activity is based on three main criteria's which are a dot-to-dot pattern which is made and easily seen, a neat image of dot-to-dot is done and a dot-to-dot line was clear with vivid-hued. This result is also supported by the interview data which indicate that the multi touch hand gestures applied on the touch screen mobile application can improve children's fine motor skills. The summarization is clearly presented in Table 1 as follows. 
The International Journal of Multimedia \& Its Applications (IJMA) Vol.10, No.6, December 2018

Table 1. The test score mean

\begin{tabular}{|l|c|c|c|c|}
\hline Age & \multicolumn{2}{|c|}{ 5 years old } & \multicolumn{2}{c|}{ 6 years old } \\
\hline Gestures/Test & $\begin{array}{c}\text { Pre-test } \\
\text { mean }\end{array}$ & $\begin{array}{c}\text { Post-test } \\
\text { mean }\end{array}$ & $\begin{array}{c}\text { Pre-test } \\
\text { mean }\end{array}$ & $\begin{array}{c}\text { Post-test } \\
\text { mean }\end{array}$ \\
\hline Multi-touch gestures & 10.88 & 12.75 & 11.25 & 13.25 \\
\hline Single-touch gestures & 11 & 12.14 & 10.71 & 10.71 \\
\hline
\end{tabular}

Table 1 summarizes the finding acquired from the pre-test and post-test by using the "Mari Belajar Bentuk" mobile application. As for multi-touch gestures, there are slightly improvement for pre-test mean and post-test mean for both 5 years old and 6 years old children with difference of 1.87 and 2 respectively. There is no difference for pre-test mean and post-test mean for children aged 6 years old involving single touch gestures.

The interview findings indicate that almost all preschool children were able to apply multi-touch hand gestures on the touch screen with easiness. This is due to the early exposure towards this kind of application by parents at home which indirectly make these children skilful.

In referring to attractiveness, they were also observed to be enjoyable to use their fingers in manipulating all the shapes of the application. In terms of efficiency, a majority of the preschool children could perform all the tasks by manipulating the shapes displayed on the touch screen using multiple fingers. Nevertheless, a minority of the children required some assistance before they could perform such tasks.

Overall, the ability of these children in performing all the tasks seemed accepted, proposing that the efficiency of the multi-touch hand gestures is quite exciting (refer to Table 2). As such, the perspicuity of the multi-touch hand gestures can be impartially deemed to be acceptable as the children in this new globalization era are quite familiar with multi-touch hand gestures on the touch screen application. Captivatingly, all the preschool children were observed to be familiar with the touch screen technology.

Table 2. The summarization of interview findings amongst teachers

\begin{tabular}{|l|c|c|}
\hline \multicolumn{1}{|c|}{ Items } & $\begin{array}{c}\text { Teacher 1 (5 years old) } \\
\text { Feedback }\end{array}$ & $\begin{array}{c}\text { Teacher 2 (6 years old) } \\
\text { Feedback }\end{array}$ \\
\hline \multicolumn{1}{|c|}{ Attractiveness } & $/$ \\
\hline Enjoyable. & $/$ & $/$ \\
\hline $\begin{array}{l}\text { Able to manipulate shapes with } \\
\text { multiple fingers. }\end{array}$ & $/$ & $/$ \\
\hline Able to perform tasks. & $/$ & $/$ \\
\hline \multicolumn{1}{|c|}{ Efficiency } & $/$ \\
\hline Able to complete tasks. & $/$ & $/$ \\
\hline Able to manipulate shapes. & \multicolumn{1}{|c|}{ Perspicuity } & \\
\hline \multicolumn{2}{|c|}{ Dependability } \\
gamiliar with multi-touch hand
\end{tabular}


The International Journal of Multimedia \& Its Applications (IJMA) Vol.10, No.6, December 2018

\begin{tabular}{|l|l|l|}
\hline \multicolumn{3}{|c|}{ Stimulation } \\
\hline $\begin{array}{l}\text { Motivate child in using the multi- } \\
\text { touch gestures. }\end{array}$ & $/$ & \\
\hline
\end{tabular}

A similar positive finding for the dependability was also observed. Apparently, the preschool children were able to use the multi-touch hand gestures without any problems. They were able to control the mobile application with multiple fingers when doing the task of manipulating the shapes. Likewise, the stimulation aspect of the multi-touch hand gestures suggesting that multitouch hand gestures used to manipulate the shapes are very attractive and can motivate children, as children prefer to use practical methods rather than theory. The used of multiple fingers to manipulate the shapes deemed to be attractive and this is the factor which motivates the children to use the multi-touch gestures continuously.

The findings of this study is similar to Mohd. Razali [17] which agreed that multi touch gestures performed on multi-touch screen design can help improve the development of fine motor skills of preschool children, especially among 5 and 6 year olds. As such, the findings of this study can be used as strategies for the designers and developers of mobile applications for children.

In particular, such strategies can help these practitioners to develop appropriate multi-touch screen designs that can support a diverse range of gestural interactions (such as free rotate gesture, pinch gesture, and spread gesture), with which such children can enhance their fine motor skills in ways that are fun, engaging, and exciting. Admittedly, more efforts are needed to examine the full impact of multi touch hand gestures on the development of children's cognitive and psychomotor abilities.

\section{CONCLUSiOnS}

The overall finding strongly suggests that multi-touch hand gestures on touch screen design can improve children's fine motor skills based on the movement of pinching, spreading and rotating. With the use of multi-touch hand gestures in mobile applications, pre-school children are capable to implement small movements naturally to complete tasks. The movements that involve the small muscles of their hands, wrists and fingers will indirectly support their fine motor skills development. Pre-school children rely on the skills to do tasks such as holding and using pencils and some other instruments appropriately. Children are not expected to be able to write if they have not yet developed the strength needed in their hands and fingers. Given that this article only reported the scores of Dot-to-dot line activity and feedback from teachers, future research should explores on the impact of multi-touch hand gestures on biological aspect of the fine motor skills development among pre-school children. However, it is also suggested that single touch gesture to be implemented for the pre-school children with either having basic knowledge or lack of exposure on touch screen technology. Then, verbal explanation with a step-by-step teaching can assist in performing multi-touch hand gestures.

\section{REFERENCES}

[1] Jain, A., Bhargava, D. B., \& Rajput, A. (2013). Touch-screen technology. International Journal of Advanced Research in Computer Science and Electronics Engineering (IJARCSEE), 2(1), pp. 74.

[2] Flewitt, R., Messer, D., \& Kucirkova, N. (2015). New directions for early literacy in a digital age: The iPad. Journal of Early Childhood Literacy, 15(3), pp. 289-310.

[3] Crescenzi, L., Jewitt, C., \& Price, S. (2014). The role of touch in preschool children's learning using iPad versus paper interaction. Australian Journal of Language and Literacy, 37(2), pp. 86. 
The International Journal of Multimedia \& Its Applications (IJMA) Vol.10, No.6, December 2018

[4] Nacher, V., Jaen, J., Navarro, E., Catala, A., \& González, P. (2015). Multi-touch gestures for prekindergarten children. International Journal of Human-Computer Studies, 73, pp. 37-51.

[5] Aziz, N. A. A. (2013). Children's interaction with tablet applications: Gestures and interface design. Children, 2(3), pp. 447-450.

[6] Agostinho, S., Tindall-Ford, S., Ginns, P., Howard, S. J., Leahy, W., \& Paas, F. (2015). Giving learning a helping hand: finger tracing of temperature graphs on an iPad. Educational Psychology Review, 27(3), pp. 427-443.

[7] Dubé, A. K., \& McEwen, R. N. (2015). Do gestures matter? The implications of using touchscreen devices in mathematics instruction. Learning and Instruction, 40, pp. 89-98.

[8] Omar, A. (2017). Permainan Mudah Alih dan Kanak-kanak. IDEALOGY, 2(1), pp. 137-149.

[9] Lin, L. Y., Cherng, R. J., \& Chen, Y. J. (2017). Effect of touch screen tablet use on fine motor development of young children. Physical \& Occupational Therapy in Pediatrics, pp. 1-11.

[10] Genc, Z. (2014). Parents' perceptions about the mobile technology use of preschool aged children. Procedia-Social and Behavioral Sciences, 146, pp. 55-60.

[11] Nachiappan, S., Jantan, R., \& Shukor, A. A. A. (2008). Psikologi pendidikan. Shah Alam: Oxford Fajar Sdn Bhd.

[12] Editors of Child magazine, Developing Motor Skills (2016), Retrieved from http://www.parents.com/toddlers-preschoolers/development/physical/child-developing-motor-skills/. on 1st March 2016.

[13] Kammer, D., Wojdziak, J., Keck, M., \& Groh, R. (2010). Towards a formalization of multi-touch gestures. Paper presented at the ITS 2010: Meta Gestures, November 7-10, 2010, Saarbrucken, Germany, pp. 49-58.

[14] Katrina Schwartz. Why Kids Need to Move, Touch and Experience to Learn, (2015). Retrieved March, 1, 2016, from http://ww2.kqed.org/mindshift/2015/03/26/why-kids-need-to-move-touch-andexperience-to-learn/.

[15] Fine motor skills (2016). Retrieved from http://www.prekinders.com/fine-motor-skills/ on 1st March 2016.

[16] Schrepp, M., Hinderks, A., \& Thomaschewski, J. (2016). Construction of a benchmark for the user experience questionnaire (UEQ). International Journal of Interactive Multimedia and Artificial Intelligence, $4\left(\mathrm{~N}^{\circ} 4\right)$, pp. 40-44.

[17] Mohd Razali, F. Abdul Aziz, N. A., Salim, S. A., Mohamad Rasli, R., \& Zulkefly, N. F. (2018). The user experiences of pre-school children on the use of multi touch hand gestures towards fine motor skills : the experts' and teachers' reviews. Journal of Fundamental and Applied Sciences. 8(X), pp. 14. 
The International Journal of Multimedia \& Its Applications (IJMA) Vol.10, No.6, December 2018 AUTHORS

Fadhlina Mohd Razali is a lecturer at Faculty of Art, Computing, and Creative Industry, Sultan Idris Education University (UPSI). Her research interest is in Child-Computer Interaction, Multimedia Application Development, Gestural Interface Design, Gamification and Early Childhood Education.

Nor Azah Abd Aziz is an associate professor at Faculty of Art, Computing and Creative Industry, Sultan Idris Education University (UPSI). Her research interest is in Gestural Interface Design, Child Computer Interaction, Multimedia Application Development, Islamic Spiritual Psychology, Information Technology, Internet / Web Filtering and Internet and Society.

Roznim Mohamad Rasli is a lecturer at Faculty of Art, Computing and Creative Industry, Sultan Idris Education University (UPSI). Her research interest is in Artificial Intelligence, Knowledge-based Systems, Knowledge Management, Data Mining/Knowledge Discovery in Databases, and Multimedia Interactive.

Siti Aisyah Salim is a senior lecturer at Faculty of Technology Management and Business, Universiti Tun Hussein Onn Malaysia (UTHM). Her research interest is in Knowledge Management, Database Management, Enterprise System, Cloud ERP, Innovation Adoption, Organisational Decision Making, and Multi-group.

Syakirah binti Samsudin is an associate professor at the Faculty of Science and Mathematic, Sultan Idris Education University. Her research interest is in Fish physiology - Cardiovascular system Early fish development Cyanobacterial toxin (Microcystins) Beta methyl-amino acid (BMAA) Conservation biology - terrestrial and freshwater Radio-tracking (Radio telemetry) Ecological Footprints Fish biodiversity

Nur Farah Zulkefly is a research assistant at the Faculty of Art, Computing and Creative Industry, Sultan Idris Education University. Her research interest is in Information Security Assurance, Information Management System, Gestural Interface Design, and Gamification.
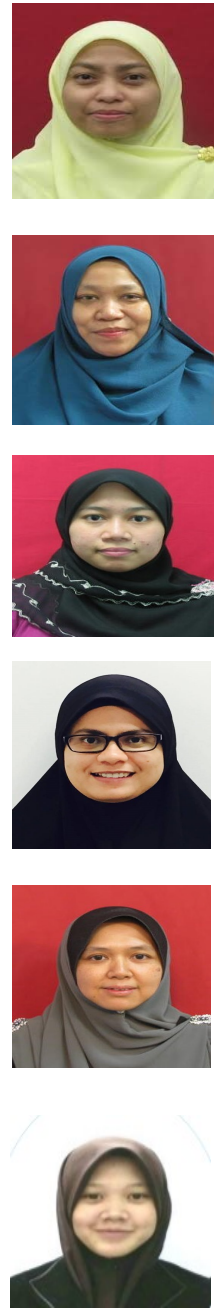